\title{
EVALUASI KEPUASAN PENGUNJUNG DAN KINERJA PENGELOLAAN WISATA ALAM PERKEMAHAN GUNUNG BUNDER TAMAN NASIONAL GUNUNG HALIMUN SALAK JAWA BARAT
}

\section{(Visitor Satisfication and Performance Evaluation of Nature Tourism in Gunung Bunder Camp, Gunung Halimun Salak National Park, West Java)}

\author{
T. MAYA SAFIRA ${ }^{1 *}$, SAMBAS BASUNI ${ }^{2)}$ DAN NANDI KOSMARYANDI ${ }^{2)}$ \\ 1) Program Studi Magister Manajemen Ekowisata dan Jasa Lingkungan, Sekolah Pasca Sarjana Institut Pertanian \\ Bogor, Kampus Darmaga, Bogor, Indonesia 16680 \\ 2) Departemen Konservasi Sumberdaya Hutan \& Ekowisata, Fakultas Kehutanan Institut Pertanian Bogor, Kampus \\ Darmaga, Bogor, Indonesia 16680
}

*Email: mayabasyir@gmail.com

Diterima 28 November 2019 / Disetujui 23 Maret 2020

\begin{abstract}
Gunung Halimun Salak National Park (TNGHS) is one of the National Parks that offers natural attractions, one of which is the Gunung Bunder Camp Site that is popular with visitors. This research was conducted to measure the level of satisfaction based on tourism activities for the development and improvement of providers/managers of camp tourism through satisfaction indicators expected by visitors. The study was conducted in September-October 2018 and July-August 2019 using Likert scale to uncover visitor perceptions by assessing 47 natural tourism indicators so that potential indicators and good indicators were obtained. This study used CSI method to determine the level of visitor satisfaction, then used the IPA method to map out the relationship between interests and the performance of each indicator. The IPA analysis in the Cartesian diagram shows seven low performance indicators that are the top priority that must be managed, then the indicators in this quadrant must be improved with indicators on the availability of information media, availability of male and female toilet, availability of trash, availability of organic and non-trash organic, ticket distribution to visitors, cleaning staff response speed, and ticket prices in accordance with the provisions. The recommendation of this research is the management of the Gunung Bunder camping ground can refer to the statutory regulations and standard provisions relating to the campsite nature tourism activities.
\end{abstract}

Keywords: Evaluation, Performance, Satisfaction, Visitor

\section{ABSTRAK}

Taman Nasional Gunung Halimun Salak (TNGHS) merupakan salah satu Taman Nasional yang menawarkan objek wisata alam, salah satu yang digemari pengunjung adalah Wisata Bumi Perkemahan Gunung Bunder. Penelitian dilakukan untuk mengukur tingkat kepuasan berbasis kegiatan wisata sebagai dasar pengembangan dan perbaikan bagi penyedia/pengelola wisata perkemahan melalui indikator kepuasan yang diharapkan oleh pengunjung. Penelitian dilakukan pada September-Oktober 2018 dan Juli-Agustus 2019 menggunakan skala Likert untuk mengungkap persepsi pengunjung dengan menilai 47 indikator wisata alam sehingga didapatkan indikator potensial dan indikator yang baik. Penelitian ini menggunakan metode CSI untuk mengetahui tingkat kepuasan pengunjung, kemudian menggunakan metode IPA untuk memetakan hubungan antara kepentingan dengan kinerja dari masing-masing indikator. Pada analisis IPA dalam diagram kartesius menunjukkan tujuh indikator kinerja rendah yang menjadi prioritas utama yang harus dikelola, maka indikator pada kuadran ini harus ditingkatkan lagi kinerjanya dengan indikator ketersediaan media informasi, ketersediaan MCK pria dan wanita, ketersediaan tempat sampah, ketersediaan tempat sampah organik dan non-organik, pendistribusian karcis kepada pengunjung, kecepatan tanggap petugas kebersihan, dan harga tiket sesuai dengan ketentuan. Rekomendasi dari penelitian ini adalah pengelolaan bumi perkemahan Gunung Bunder dapat mengacu pada peraturan perundangundangan dan ketentuan standar yang berhubungan dengan kegiatan wisata alam perkemahan.

Kata kunci: evaluasi, kinerja, kepuasan, pengunjung

\section{PENDAHULUAN}

Indonesia memiliki kekayaan sumberdaya alam yang sangat tinggi dengan karakteristik berbeda-beda sehingga masing-masing memiliki keunggulan komparatif dan kompetitif. Kekayaan sumberdaya alam tersebut perlu dimanfaatkan sebesar-besarnya untuk kesejahteraan rakyat dengan tetap mempertahankan keanekaragaman, potensi, dan nilainya guna memenuhi kebutuhan dan aspirasi generasi yang akan datang. Salah satu kekayaan sumberdaya alam di Indonesia terdapat di Taman Nasional. Taman Nasional Gunung Halimun Salak (TNGHS) merupakan salah satu Taman Nasional di Indonesia yang menawarkan objek wisata alam. TNGHS memiliki beragam objek dan daya tarik wisata alam berupa gejala alam, keindahan alam, dan kekayaan hayati yang menarik perhatian pengunjung. Salah satu destinasi wisata alam di TNGHS adalah Wisata Alam Gunung Bunder (WAGB). WAGB memiliki paling sedikit sepuluh ODTWA di antaranya adalah Bumi 
Perkemahan Gunung Bunder, Pendakian Kawah Ratu, Pemandian Air Panas, Curug Ngumpet I, Curug Ngumpet II, Curug Cihurang, Curug Seribu, Curug Geblug, Curug Pangeran, dan Curug Cigamea. Letaknya yang strategis dan kemudahan akses menjadikan wisata alam Gunung Bunder menjadi pilihan banyak wisatawan untuk mengisi waktu luangnya dengan menikmati kesegaran dan keindahan alam (Ekayani et al. 2014). Jumlah pengunjung yang terus meningkat ke kawasan wisata alam Gunung Bunder akan berdampak buruk pada aspek sumberdaya alam, sosial, dan kinerja sehingga mempengaruhi kepuasan pengunjug.

Penelitian ini dilakukan untuk mengukur tingkat kepuasan pengunjung berbasis kegiatan wisata alam untuk pengembangan dan perbaikan bagi pengelola bumi perkemahan agar diketahui indikator kepuasan yang diinginkan oleh pengunjung. Penelitian dilakukan pada kegiatan berkemah karena kegiatan ini merupakan bentuk rekreasi alam pada kawasan hutan konservasi yang paling digemari meskipun pada tahun 2016 tercatat hasil data kunjungan di Bumi Perkemahan Gunung Bunder berada pada jumlah yang terkecil yaitu 365 orang (Jubei et al. 2017). Data kunjungan tersebut yang masih rendah, maka penting untuk melakukan penelitian untuk mengetahui faktor-faktor penyebab berkurangnya jumlah kunjungan tersebut.

Tujuan penelitian adalah mengidentifikasi indikator potensial wisata alam kegiatan berkemah, mengidentifikasi indikator yang baik untuk wisata alam kegiatan berkemah, mendapatkan nilai tingkat kepuasan pengunjung, mendapatkan indikator-indikator kinerja rendah serta merumuskan saran pengelolaan untuk peningkatan kinerja indikator.

\section{METODE PENELITIAN}

Penelitian dilaksanakan di Taman Nasional Gunung Halimun Salak, tepatnya di Bumi Perkemahan Gunung Bunder yang terletak di Desa Gunung Bunder II Kecamatan Pamijahan, Kabupaten Bogor, Provinsi Jawa Barat. Penelitian dilaksanakan pada September-Oktober 2018 dan Juli-Agustus 2019. Jenis data yang dikumpulkan dalam penelitian ini terdiri dari data primer dan sekunder. Data primer diperoleh dengan mengambil dokumentasi dan wawancara menggunakan kuesioner terhadap pengunjung sedangkan data sekunder dengan penelusuran studi pustaka. Data persepsi pengunjung dikumpulkan menggunakan metode accidental sampling dengan pengambilan sampel berdasarkan siapa saja yang ditemui secara kebetulan dan cocok dijadikan sebagai sumber data (Sugiyono 2003) sejumlah 30 responden. Menurut Sekaran (2006) jumlah responden yang dibutuhkan untuk hasil penelitian yang baik minimal sebanyak 30 responden.

Penelitian ini menggunakan skala Likert dengan modifikasi untuk mengungkap persepsi sehingga dapat diketahui apakah persepsi seseorang positif atau negatif terhadap suatu hal atau objek (Keliwar dan Nurcahyo
2015). Pengukuran dilakukan dengan menilai 27 indikator unsur fasilitas, 18 indikator unsur pelayanan pengunjung, 11 indikator unsur sumberdaya alam, dan sembilan indikator unsur pengaturan pengunjung. Responden memilih skor 1-5 yang bermakna sangat tidak penting/puas, tidak penting/puas, cukup penting/puas, penting/puas dan sangat penting/puas. Penilaian tersebut menghasilkan indikator potensial yaitu indikator yang bernilai penting hingga bernilai sangat penting. Dari beberapa indikator potensial dapat diidentifikasi indikator yang memenuhi ciri/kriteria indikator yang baik menurut Manning (2007) yang dinilai oleh ahli wisata dan didapat nilai indikator penting sampai sangat penting.

Metode yang digunakan untuk mengetahui tingkat kepuasan pengunjung adalah Customer Satisfaction Index (CSI). CSI digunakan untuk mengetahui tingkat kepuasan pengunjung secara menyeluruh dengan melihat tingkat kepentingan dan kepuasan dari setiap variabel (Anggraini et al. 2015) dengan rumus yang digunakan Aritonang (2005):

$$
\text { CSI }=\frac{\sum_{i=1}^{p} W S i}{H S} x 100 \%
$$

Keterangan:

$\mathrm{p} \quad=$ Atribut kepentingan ke- $\mathrm{p}$

$\mathrm{HS}=$ (Highest Scale) skala maksimum yang digunakan.

Metode selanjutnya dengan menggunakan Importance Performance Analysis (IPA). IPA digunakan untuk memetakan hubungan antara kepentingan dengan kepuasan dari masing-masing indikator. Penggunaan IPA saat ini sudah berkembang dan sangat membantu dalam menganalisis dan membangun model potensi ekowisata secara optimal (Xue dan Fang 2018). Tahapan analisis IPA yang dimodifikasi sebagai berikut:

1. Menghitung rata-rata tingkat kepentingan dan tingkat kepuasan setiap indikator:

$$
\bar{X}=\frac{\sum X i}{n} \quad \bar{Y}=\frac{\sum Y i}{n}
$$

Keterangan:

$$
\begin{aligned}
\frac{\mathrm{X}}{\mathrm{Y}} & =\text { nilai rata-rata kepuasan indikator } \\
\mathrm{n} & =\text { nilai rata-rata kepentingan indikator }
\end{aligned}
$$

2. Membuat nilai tengah untuk membuat diagram kartesius :

$$
\begin{aligned}
\overline{\bar{X}} & =\frac{\text { Nilai skor tertinggi }+ \text { Nilai skor terendah }}{2} \\
\overline{\bar{Y}} & =\frac{\text { Nilai skor tertinggi }+ \text { Nilai skor terendah }}{2}
\end{aligned}
$$

3. Hasil perhitungan tersebut diplotkan dalam diagram kartesius seperti pada Gambar 1.

Diagram ini terdiri dari empat kuadran. Kuadran I (prioritas utama), memuat indikator yang dianggap penting oleh pengunjung, tetapi nilai kepuasan belum sesuai harapan pengunjung. Indikator dalam kuadran ini harus ditingkatkan lagi kinerjanya agar dapat memuaskan pengunjung. Kuadran II (pertahankan prestasi), memuat indikator yang dianggap penting oleh pengunjung dan 
memiliki nilai kepuasan yang tinggi, indikator ini perlu dipertahankan kinerjanya. Kuadran III (prioritas rendah), memuat indikator yang dianggap kurang penting oleh pengunjung dan nilai kepuasan rendah. Peningkatan terhadap indikator pada kuadran ini dapat dipertimbangkan kembali karena manfaat bagi pengunjung sangat kecil. Kuadran IV (berlebihan), memuat indikator yang dianggap kurang penting oleh pengunjung, tetapi memiliki nilai kepuasan yang tinggi. Peningkatan kinerja indikator pada kuadran ini menyebabkan terjadinya pemborosan sumberdaya.

Saran rumusan didapatkan melalui sintesis atas temuan hasil penelitian dengan peraturan perundangundangan dan ketentuan standar yang berhubungan dengan kegiatan wisata alam seperti Standar Pelayanan Masyarakat Pariwisata Alam (PSLK 2015) dalam Peraturan Menteri Pariwisata No 24 Tahun 2015 tentang Standar Usaha Bumi Perkemahan, Peraturan Direktur Jenderal Perlindungan Hutan dan Konservasi Alam (PHKA) No P.02/IV-SET/2012 Tahun 2012 tentang Sarana Pariwisata Alam di Taman Nasional, Tahura, dan Taman Wisata Alam dan seperti yang dikemukakan oleh Douglass (1969) dan Bell (2008) tentang berkemah.
HASIL DAN PEMBAHASAN

\section{Indikator Potensial dan Indikator yang Baik}

\section{a. Unsur fasilitas}

Pada unsur fasilitas kegiatan berkemah, dari 27 indikator yang diteliti teridentifikasi 26 indikator potensial dan 18 indikator yang baik (Tabel 1).

\section{b. Unsur Pelayanan Pengunjung}

Pada unsur pelayanan pengunjung kegiatan berkemah, dari 18 indikator yang diteliti teridentifikasi 16 indikator potensial dan 13 indikator yang baik (Tabel 2).

\section{c. Unsur Sumberdaya Alam}

Pada unsur sumberdaya alam kegiatan berkemah, dari 11 indikator yang diteliti teridentifikasi 9 indikator potensial dan 7 indikator yang baik (Tabel 3).

\section{d. Unsur Pengaturan Pengunjung}

Pada unsur pengaturan pengunjung kegiatan berkemah, 9 indikator yang diteliti semuanya merupakan indikator potensial dan indikator yang baik (Tabel 4).

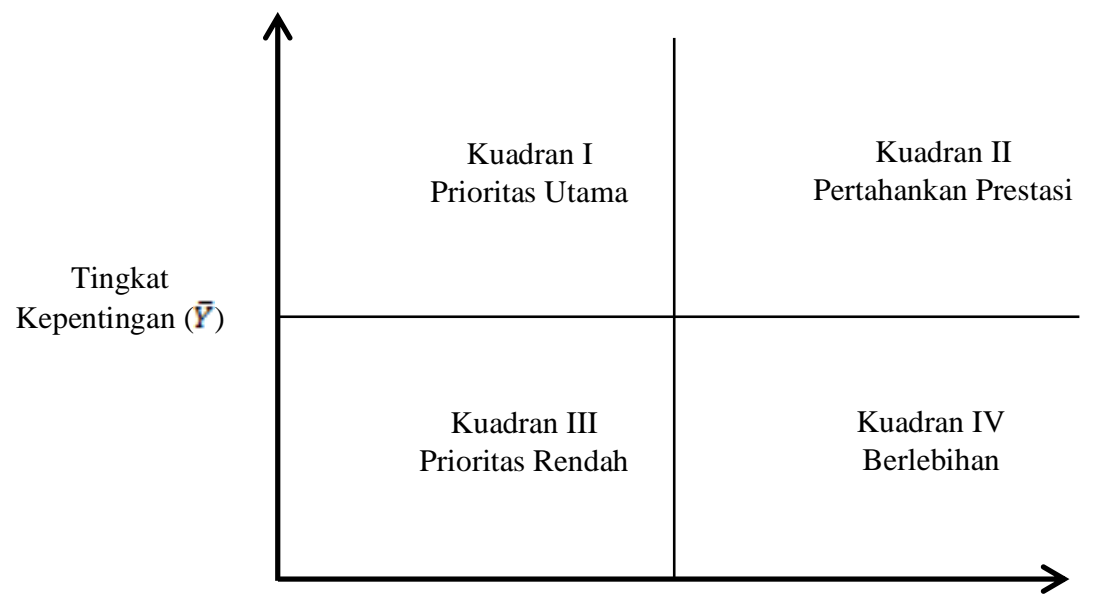

Tingkat Kepuasan $(\bar{X})$

Gambar 1 Diagram kartesius IPA

Tabel 1 Hasil identifikasi indikator unsur fasilitas

\begin{tabular}{|c|c|c|c|}
\hline Atribut & Indikator yang diteliti & $\begin{array}{l}\text { Indikator } \\
\text { potensial }\end{array}$ & $\begin{array}{l}\text { Indikator } \\
\text { yang baik }\end{array}$ \\
\hline \multirow[t]{2}{*}{ 1. Area parkir } & 1. Ketersediaan area parkir di dalam lokasi wisata & $\sqrt{ }$ & $\sqrt{ }$ \\
\hline & 2. Ketersediaan area parkir di luar lokasi wisata & $\sqrt{ }$ & \\
\hline \multirow[t]{3}{*}{ 2. Akses jalan } & 3. Waktu tempuh menuju lokasi & $\sqrt{ }$ & $\sqrt{ }$ \\
\hline & 4. Jarak tempuh dari pintu masuk ke tempat kegiatan & $\sqrt{ }$ & $\sqrt{ }$ \\
\hline & 5. Jalan dengan pengerasan & $\sqrt{ }$ & \\
\hline \multirow[t]{4}{*}{ 3. Papan petunjuk } & 6. Ketersediaan papan nama & $\sqrt{ }$ & $\sqrt{ }$ \\
\hline & 7. Ketersediaan papan informasi & $\sqrt{ }$ & $\sqrt{ }$ \\
\hline & 8. Ketersediaan papan petunjuk arah & $\sqrt{ }$ & $\sqrt{ }$ \\
\hline & 9. Ketersediaan papan larangan/ peringatan & $\sqrt{ }$ & $\sqrt{ }$ \\
\hline
\end{tabular}


Tabel 1 Hasil identifikasi indikator unsur fasilitas (Lanjutan)

\begin{tabular}{llcc}
\multicolumn{1}{c}{ Atribut } & \multicolumn{1}{c}{ Indikator yang diteliti } & $\begin{array}{c}\text { Indikator } \\
\text { potensial }\end{array}$ & $\begin{array}{c}\text { Indikator } \\
\text { yang baik }\end{array}$ \\
\hline 4. Media informasi & 10. Ketersediaan media informasi & $\sqrt{ }$ & $\sqrt{ }$ \\
5. MCK & 11. Ketersediaan MCK pria dan wanita & $\sqrt{ }$ & $\sqrt{ }$ \\
& 12. Kondisi drainase lancar & $\sqrt{ }$ & $\sqrt{ }$ \\
& 13. Drainase dibangun tertutup & $\sqrt{ }$ & $\sqrt{ }$ \\
& 14. Ketersediaan fentilasi & $\sqrt{ }$ & $\sqrt{ }$ \\
15. Sirkulasi udara dan pencahayaan yang baik & Tempat sampah & 16. Ketersediaan tempat sampah & $\sqrt{ }$ \\
& 17. Ketersediaan tempat sampah organik dan non-organik & $\sqrt{ }$ & $\sqrt{ }$ \\
7. Tempat ibadah & 18. Ketersediaan tempat sampah tertutup & $\sqrt{ }$ \\
8. Kantin/tempat jajanan & 19. Kelayakan penggunaan tempat ibadah & 20. Kecukupan kantin/tempat jajanan & $\sqrt{ }$ \\
9. Media komunikasi & 21. Ketersediaan media komunikasi & $\sqrt{ }$ \\
10. Pos keamanan & 22. Ketersediaan pos keamanan & $\sqrt{ }$ \\
11. Pos keselamatan & 23. Ketersediaan pos keselamatan & $\sqrt{ }$ \\
12. Jaringan air bersih & 24. Ketersediaan air bersih & $\sqrt{ }$ & $\sqrt{ }$ \\
& 25. Kontinyuitas ketersediaan air bersih & 26. Dibangun di dalam tanah & $\sqrt{ }$
\end{tabular}

Tabel 2 Hasil identifikasi indikator unsur pelayanan pengunjung.

\begin{tabular}{|c|c|c|c|}
\hline Atribut & Indikator yang diteliti & $\begin{array}{l}\text { Indikator } \\
\text { potensial }\end{array}$ & $\begin{array}{c}\text { Indikator yang } \\
\text { baik }\end{array}$ \\
\hline \multirow[t]{3}{*}{ 1. Tiket } & 1. Pendistribusian karcis kepada pengunjung & $\sqrt{ }$ & $\sqrt{ }$ \\
\hline & 2. Kecepatan melayani kedatangan tamu & $\sqrt{ }$ & $\sqrt{ }$ \\
\hline & 3. Kecepatan melayani kebutuhan tamu & $\sqrt{ }$ & $\sqrt{ }$ \\
\hline \multirow[t]{3}{*}{ 2. Pemanduan } & 4. Jumlah pemandu & & \\
\hline & 5. Tingkat Pengetahuan & $\sqrt{ }$ & $\sqrt{ }$ \\
\hline & 6. Bersertifikat & & \\
\hline \multirow[t]{2}{*}{ 3. Informasi } & 7. Kemampuan menanggapi saran dan keluhan & $\sqrt{ }$ & $\sqrt{ }$ \\
\hline & 8. Kemampuan memberi rasa aman & $\sqrt{ }$ & $\sqrt{ }$ \\
\hline \multirow[t]{4}{*}{ 4. Pengamanan dan keselamatan } & 9. Jumlah pengamanan dan keselamatan & $\sqrt{ }$ & $\sqrt{ }$ \\
\hline & 10. Kompetensi & $\sqrt{ }$ & $\sqrt{ }$ \\
\hline & 11. Cepat tanggap & $\sqrt{ }$ & $\sqrt{ }$ \\
\hline & 12. Kemampuan & $\sqrt{ }$ & $\sqrt{ }$ \\
\hline \multirow[t]{3}{*}{ 5. Penampilan } & 13. Kerapihan & $\sqrt{ }$ & \\
\hline & 14. Identitas/tanda pengenal & $\sqrt{ }$ & \\
\hline & 15. Pakaian seragam & $\sqrt{ }$ & \\
\hline \multirow[t]{2}{*}{ 6. P3K } & 16. Cepat taggap & $\sqrt{ }$ & $\sqrt{ }$ \\
\hline & 17. Kemampuan & $\sqrt{ }$ & $\sqrt{ }$ \\
\hline 7. Kebersihan & 18. Cepat tanggap & $\sqrt{ }$ & $\sqrt{ }$ \\
\hline Jumlah $\sqrt{ }$ & 18 & 16 & 13 \\
\hline
\end{tabular}


Tabel 3 Hasil identifikasi indikator unsur sumberdaya alam

Atribut $\quad$ Indikator yang diteliti Indikator potensial $\quad$ Indikator yang baik

\begin{tabular}{|c|c|c|c|}
\hline \multirow[t]{2}{*}{ 1. Kondisi tanah } & 1. Kemiringan lahan & $\sqrt{ }$ & $\sqrt{ }$ \\
\hline & 2. Tidak ada genangan & $\sqrt{ }$ & $\sqrt{ }$ \\
\hline 2. Kondisi bebatuan & 3. Adanya batu bongkahan & & \\
\hline 3. Tumbuhan & 4. Keberadaan jenis & $\sqrt{ }$ & $\sqrt{ }$ \\
\hline 4. Satwaliar & 5. Keberadaan jenis & & \\
\hline \multirow[t]{2}{*}{ 5. Sumberdaya air } & 6. Digunakan untuk MCK & $\sqrt{ }$ & $\sqrt{ }$ \\
\hline & 7. Digunakan untuk memasak & $\sqrt{ }$ & $\sqrt{ }$ \\
\hline 6. Pemandangan alam & 8. Keindahan & $\sqrt{ }$ & $\sqrt{ }$ \\
\hline 7. Luas area & 9. Kecukupan lahan untuk beraktivitas & $\sqrt{ }$ & $\sqrt{ }$ \\
\hline \multirow[t]{2}{*}{ 8. Terapi alam } & 10. Suara-suara alami & $\sqrt{ }$ & \\
\hline & 11. Kesegaran alami & $\sqrt{ }$ & \\
\hline
\end{tabular}

$$
\text { Jumlah } \sqrt{ }
$$

11

9

7

Tabel 4 Hasil identifikasi indikator unsur pengaturan pengunjung.

\begin{tabular}{|c|c|c|c|}
\hline Atribut & Indikator yang diteliti & $\begin{array}{l}\text { Indikator } \\
\text { potensial }\end{array}$ & $\begin{array}{c}\text { Indikator yang } \\
\text { baik }\end{array}$ \\
\hline 1. Pembagian tempat kegiatan & 1. Jarak antar kelompok kegiatan & $\sqrt{ }$ & $\sqrt{ }$ \\
\hline \multirow[t]{3}{*}{ 2. Perilaku pengunjung } & 2. Tidak terjadi gangguan antar pengunjung & $\sqrt{ }$ & $\sqrt{ }$ \\
\hline & 3. Tidak ada vandalisme & $\sqrt{ }$ & $\sqrt{ }$ \\
\hline & 4. Tidak ada kebisingan & $\sqrt{ }$ & $\sqrt{ }$ \\
\hline \multirow[t]{2}{*}{ 3. Harga tiket } & 5. Sesuai dengan ketentuan & $\sqrt{ }$ & $\sqrt{ }$ \\
\hline & 6. Terjangkau & $\sqrt{ }$ & $\sqrt{ }$ \\
\hline \multirow[t]{3}{*}{ 4. Prosedur penerimaan pengunjung } & 7. Pendaftaran & $\sqrt{ }$ & $\sqrt{ }$ \\
\hline & 8. Penanganan check in dan check out & $\sqrt{ }$ & $\sqrt{ }$ \\
\hline & 9. Pelaksanaan waktu pembayaran & $\sqrt{ }$ & $\sqrt{ }$ \\
\hline Jumlah $\sqrt{ }$ & 9 & 9 & 9 \\
\hline
\end{tabular}

\section{Customer Satisfaction Index (CSI)}

Nilai indeks kepuasan pengunjung terhadap indikator yang baik pada kegiatan berkemah adalah $68 \%$, artinya pengunjung merasa puas melakukan kegiatan berkemah di Bumi Perkemahan Gunung Bunder. Berdasarkan hal tersebut, pengelola harus menjaga dan mempertahankan semua indikator yang baik.

\section{Importance Performance Analysis (IPA) Indikator yang Baik}

Hasil pemetaan nilai kepentingan dan kepuasan indikator yang baik pada diagram kartesius terdapat indikator-indikator berada pada kuadran I dan II. Peningkatan pengelolaan kinerja dilihat pada indikator yang berada pada kuadran I yaitu indikator kinerja rendah yang menjadi prioritas utama dalam pengelolaan.

\section{a. Unsur fasilitas}

Indikator yang tersebar di kuadran I sebanyak 4 indikator yang disajikan pada Gambar 2. Hasil analisis menunjukkan indikator yang berada pada kuadran I adalah ketersediaan media informasi, ketersediaan MCK pria dan wanita, ketersediaan tempat sampah, dan ketersediaan tempat sampah organik dan non-organik artinya bahwa indikator-indikator tersebut dianggap penting oleh pengunjung kegiatan berkemah, tetapi kepuasannya belum sesuai harapan pengunjung. Indikator dalam kuadran ini harus ditingkatkan lagi kinerjanya agar dapat memuaskan pengunjung.

Hasil penelitian yang sama dari Wade dan Eagles (2003) menjelaskan indikator ketersediaan informasi yang berada di kuadran I menjadi perhatian khusus di Taman Nasional Kilimanjaro. Hal ini juga ditegaskan dalam Undang-Undang Nomor 10 Tahun 2009 tentang Kepariwisataan pada Pasal 20 ayat (a) yang menyatakan bahwa setiap wisatawan berhak memperoleh informasi yang akurat mengenai daya tarik wisata. Sama halnya pada indikator ketersediaan MCK pria dan wanita yang tercantum pada lampiran Peraturan Menteri Pariwisata Nomor 24 Tahun 2015 yang menjelaskan bahwa kamar mandi dan toilet yang bersih, terawat dan terpisah untuk pria dan wanita sesuai dengan kapasitas pengunjung. Kemudian indikator ketersediaan tempat sampah, ketersediaan tempat sampah organik dan non-organik, 
kedua indikator tersebut sudah tercantum pada lampiran Peraturan Menteri Pariwisata Nomor 24 Tahun 2015 tentang Standar Usaha Bumi Perkemahan yang seharusnya di bumi perkemahan Gunung Bunder disediakan tempat sampah.

\section{b. Unsur pelayanan pengunjung}

Indikator yang tersebar di kuadran I sebanyak 2 indikator yang disajikan pada Gambar 3. Indikator yang terdapat pada kuadran I adalah pendistribusian karcis kepada pengunjung dan cepat tanggap petugas kebersihan yang dinilai penting oleh pengunjung kegiatan berkemah, tetapi kepuasannya belum sesuai harapan pengunjung sehingga indikator-indikator tersebut harus ditingkatkan lagi kinerjanya agar dapat memuaskan pengunjung karena masih terlihat sampah berserakan di areal perkemahan.

\section{c. Unsur sumberdaya alam}

Pada unsur sumberdaya alam tidak ada indikator yang berada pada kuadran I (Gambar 4). Indikator yang berada pada kuadran II dianggap penting oleh pengunjung kegiatan berkemah dan memiliki nilai kepuasan yang tinggi. Indikator tersebut perlu dipertahankan kinerjanya.

\section{d. Unsur pengaturan pengunjung}

Indikator yang tersebar di kuadran I sebanyak 1 indikator yang disajikan pada Gambar 5. Hasil analisis diagram menunjukan bahwa indikator harga karcis sesuai dengan ketentuan berada pada kuadran I, artinya indikator tersebut dianggap penting oleh pengunjung kegiatan berkemah, tetapi kepuasannya belum sesuai harapan pengunjung. Indikator dalam kuadran ini harus ditingkatkan lagi kinerjanya agar dapat memuaskan pengunjung.

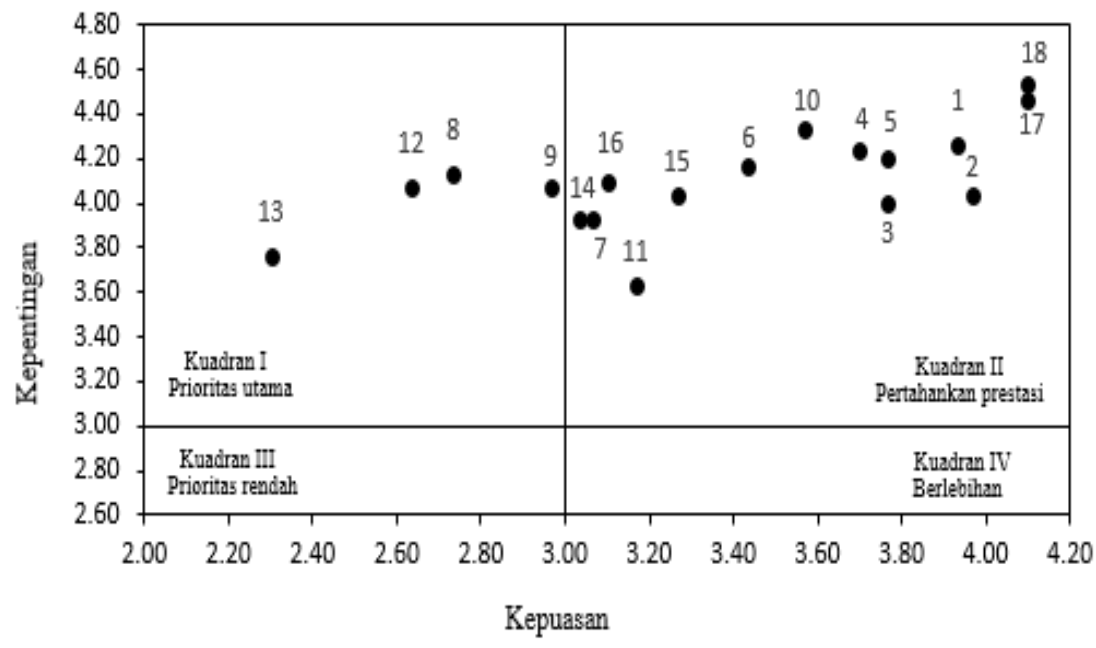

Keterangan: Kuadran I: (8) Ketersediaan media informasi; (9) Ketersediaan MCK pria dan wanita; (12) Ketersediaan tempat sampah; (13) Ketersediaan tempat sampah organik dan non-organik

Gambar 2 Diagram kartesius IPA indicator yang baik unsur fasilitas.

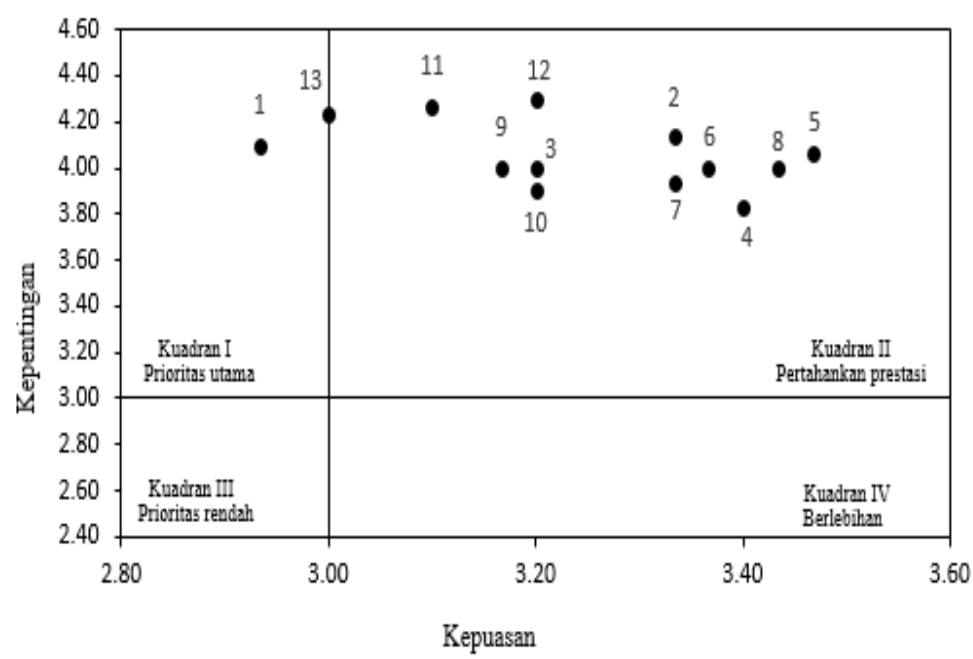

Keterangan: Kuadran I: (1) Pendistribusian karcis kepada pengunjung; (13) Cepat tanggap petugas kebersihan Gambar 3 Diagram kartesius IPA indikator yang baik unsur pelayanan pengunjung. 


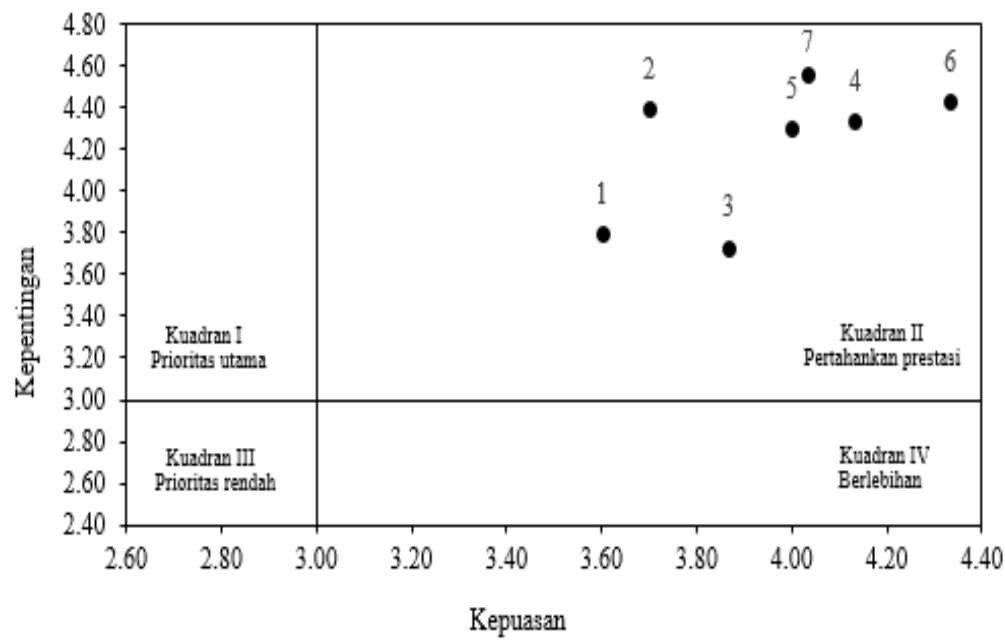

Keterangan: Kuadran I: Tidak ada indikator

Gambar 4 Diagram kartesius IPA indikator yang baik unsur sumberdaya alam.

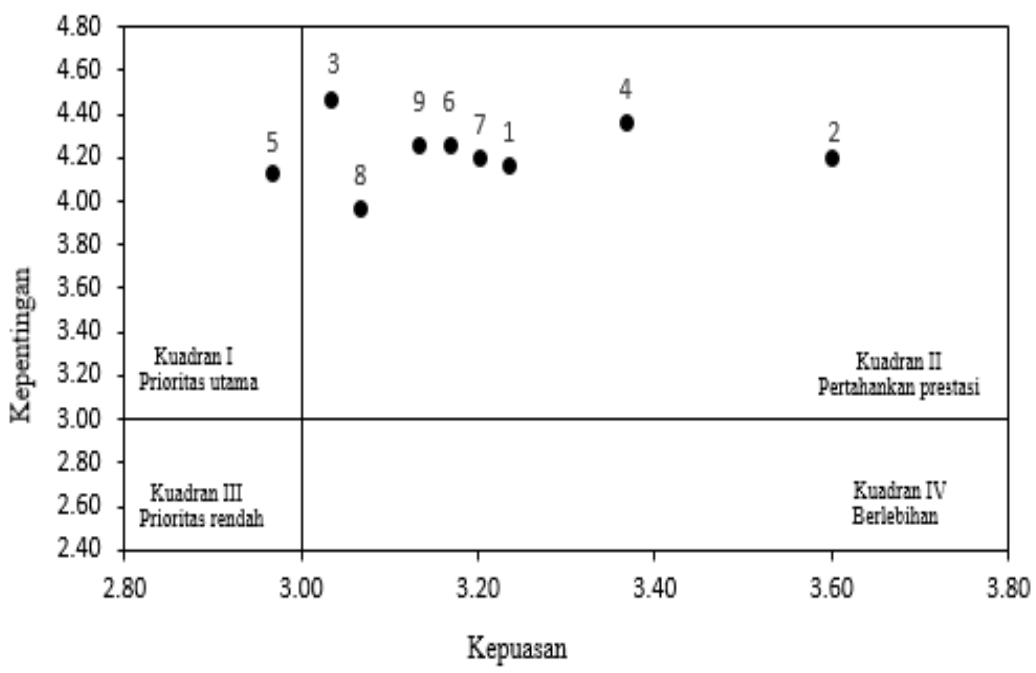

Keterangan: Kuadran I: Harga karcis sesuai dengan ketentuan

(5) Gambar 5 Diagram kartesius IPA indikator yang baik unsur pengaturan pengunjung.

\section{Saran Peningkatan Pengelolaan Indikator Kinerja Rendah}

Berdasarkan hasil dari pemetaan IPA terdapat tujuh indikator yang berada pada kuadran I yang artinya indikator kinerja rendah dan menjadi prioritas utama dalam pengelolaan kegiatan berkemah di Bumi Perkemahan Gunung Bunder. Ketujuh indikator tersebut dianalisis dengan peraturan perundang-undangan dan ketentuan standar yang berhubungan dengan kegiatan wisata alam. Hasil analisis dijadikan sebagai saran pengelolaan untuk peningkatan kinerja indikator yang dapat dilihat pada Tabel 5 .

Dari tujuh indikator kinerja rendah terdapat lima indikator yang sudah dimuat dalam peraturan perundangundangan dan ketentuan standar yang berhubungan dengan kegiatan wisata alam, yaitu ketersediaan media informasi, ketersediaan MCK pria dan wanita, ketersediaan tempat sampah, ketersediaan tempat sampah organik dan non-organik, dan pendistribusian karcis kepada pengunjung, maka saran bagi pengelola seharusnya mengikuti peraturan perundang-undangan dan ketentuan standar yang berhubungan dengan kegiatan wisata alam yang berlaku karena indikatorindikator tersebut sudah dimuat.

Saran selanjutnya dengan menganalisis tujuh indikator kinerja rendah hasil penelitian dengan pendapat yang dikemukakan oleh Douglass (1969) dan Bell (2008) tentang berkemah yang dapat dijadikan acuan bagi pengelola di Bumi Perkemahan Gunung Bunder (Tabel 6). Pada tujuh indikator kinerja rendah, empat indikator di antaranya yaitu ketersediaan MCK pria dan wanita, ketersediaan tempat sampah, ketersediaan tempat sampah organik dan non-organik, dan cepat tanggap petugas kebersihan agar dikelola secara optimal dengan mengacu pada apa yang dikemukakan oleh Douglass (1969) dan Bell (2008). 
Tabel 5 Analisis indikator kinerja rendah dengan peraturan

\begin{tabular}{|c|c|c|c|c|}
\hline \multirow{2}{*}{ No } & \multirow{2}{*}{ Indikator kinerja rendah } & \multicolumn{3}{|c|}{ Dimuat dalam peraturan perundang-undangan } \\
\hline & & 1 & 2 & 3 \\
\hline 1 & Ketersediaan media informasi & $\sqrt{ }$ & $\mathrm{x}$ & $\sqrt{ }$ \\
\hline 2 & Ketersediaan MCK pria dan wanita & $\mathrm{x}$ & $\sqrt{ }$ & $\mathrm{x}$ \\
\hline 3 & Ketersediaan tempat sampah & $\mathrm{x}$ & $\sqrt{ }$ & $\sqrt{ }$ \\
\hline 4 & Ketersediaan tempat sampah organik dan non-organik & $\mathrm{x}$ & $\sqrt{ }$ & $\mathrm{x}$ \\
\hline 5 & Pendistribusian karcis kepada pengunjung & $\mathrm{x}$ & $\sqrt{ }$ & $\mathrm{x}$ \\
\hline 6 & Cepat tanggap petugas kebersihan & $\mathrm{x}$ & $\mathrm{x}$ & $\mathrm{x}$ \\
\hline \multirow[t]{3}{*}{7} & Harga karcis sesuai dengan ketentuan & $\mathrm{x}$ & $\mathrm{x}$ & $\mathrm{x}$ \\
\hline & Jumlah $\sqrt{ }$ & 1 & 4 & 2 \\
\hline & Jumlah $\mathrm{x}$ & 6 & 3 & 5 \\
\hline
\end{tabular}

Keterangan: $\sqrt{ }=$ Sudah dimuat; $\mathrm{x}=$ Belum dimuat, $1=$ Peraturan Direktur Jenderal Perlindungan Hutan dan Konservasi Alam Nomor P.02/IV-SET/2012 Tahun 2012 tentang Sarana Pariwisata Alam di Taman Nasional, Tahura, dan Taman Wisata Alam; $2=$ Peraturan Menteri Pariwisata Nomor 24 Tahun 2015 tentang Standar Usaha Bumi Perkemahan; 3 = Standar Pelayanan Masyarakat Pariwisata Alam (PSLK 2015)

Tabel 6 Analisis indikator kinerja rendah dengan pakar

\begin{tabular}{|c|c|c|c|}
\hline No & Indikator kinerja rendah & Douglass (1969) & Bell (2008) \\
\hline 1 & $\begin{array}{l}\text { Ketersediaan media } \\
\text { informasi }\end{array}$ & - & - \\
\hline 2 & $\begin{array}{l}\text { Ketersediaan MCK pria } \\
\text { dan wanita }\end{array}$ & Toilet untuk setiap jenis kelamin & $\begin{array}{l}\text { Bangunan MCK dipisah untuk } \\
\text { pria dan wanita }\end{array}$ \\
\hline 3 & $\begin{array}{l}\text { Ketersediaan tempat } \\
\text { sampah }\end{array}$ & $\begin{array}{l}\text { - Tempat sampah terbuat dari kaleng dan } \\
\text { tertutup untuk setiap tenda }\end{array}$ & Tersedia tempat sampah \\
\hline 4 & $\begin{array}{l}\text { Katersediaan tempat } \\
\text { sampah organik dan non- } \\
\text { organik }\end{array}$ & $\begin{array}{l}\text { - Ditempatkan di tepi depan setiap tenda atau } \\
\text { berbatasan dengan jalan sehingga dapat } \\
\text { diakses untuk diambil serta nyaman bagi } \\
\text { pengguna } \\
\text { - Bahan terbuat dari kaleng, kedap air, tidak } \\
\text { menyerap air dan mudah dicuci } \\
\text { - Aman dari gangguan hewan }\end{array}$ & \\
\hline 5 & $\begin{array}{l}\text { Pendistribusian karcis } \\
\text { kepada pengunjung }\end{array}$ & - & - \\
\hline 6 & $\begin{array}{l}\text { Cepat tanggap petugas } \\
\text { kebersihan }\end{array}$ & Pembersihan dilakukan secara berkala & \\
\hline 7 & $\begin{array}{l}\text { Harga karcis sesuai dengan } \\
\text { ketentuan }\end{array}$ & - & - \\
\hline
\end{tabular}

\section{SIMPULAN}

Wisata alam kegiatan berkemah teridentifikasi dari 65 indikator yang diteliti terdapat 60 indikator potensial dan 47 indikator yang baik. Nilai indeks kepuasan pengunjung terhadap indikator yang baik pada kegiatan berkemah adalah 68\%, hal ini menunjukkan bahwa pengunjung merasa puas melakukan kegiatan berkemah di Bumi Perkemahan Gunung Bunder. Terdapat tujuh indikator kinerja rendah pada indikator yang baik yang menjadi prioritas utama dalam pengelolaan, yaitu ketersediaan media informasi, ketersediaan MCK pria dan wanita, ketersediaan tempat sampah, ketersediaan tempat sampah organik dan non-organik, pendistribusian karcis kepada pengunjung, cepat tanggap petugas kebersihan, dan harga tiket sesuai dengan ketentuan. Dari tujuh indikator tersebut, lima indikator kinerja rendah sudah dimuat dalam peraturan perundang-undangan dan ketentuan standar yang berhubungan dengan kegiatan wisata alam dan empat indikator tentang berkemah berdasarkan Douglass (1969) dan Bell (2008). Pengelolaan bumi perkemahan Gunung Bunder dapat mengacu pada peraturan perundang-undangan dan ketentuan standar yang berhubungan dengan kegiatan wisata alam perkemahan. 


\section{DAFTAR PUSTAKA}

Anggraini LD, Doeranto P, Ikasari DM. 2015. Analisis persepsi konsumen menggunakan Metode Importance Performance Analysis dan Customer Satisfaction Index. Jurnal Industri. 4 (2): 74-81.

Aritonang RI. 2005. Kepuasan Pelanggan. Jakarta: Gramedia Pustaka Utama.

Bell S. 2008. Design for Outdoor Recreation. Ed ke-7. New York: Taylor and Francis.

Douglass RW. 1969. Forest Recreation. New York: Pegramon.

Ekayani M, Nuva, Yasmin R, Shaffitri LR, Idris B. 2014. Taman Nasional untuk siapa? Tantangan membangun wisata alam berbasis masyarakat di Taman Nasional Gunung Halimun Salak. Risalah Kebijakan Pertanian dan Lingkungan. 1 (1): 46-52.

Jubei S, Kusumoarto A, Ernawati A. 2017. Analisis trend pengunjung objek ekowisata di Kawasan Resor Gunung Salak II, Taman Nasional Gunung Halimun Salak. Prosiding Temu Ilmiah IPLBI 2017: 25-30.

Keliwar S, Nurcahyo A. 2015. Motivasi dan persepsi pengunjung terhadap objek wisata Desa Budaya Pampang di Samarinda. Jurnal Manajemen Resort dan Leisure. 12 (2):10-27.

Manning RE. 2007. Park and Carrying Capacity Commons Without Tragedy. Washington: Island Press.
Pemerintah Republik Indonesia. Undang-Undang Nomor 10 tahun 2009 tentang Kepariwisataan.

Peraturan Direktur Jenderal Perlindungan Hutan dan Konservasi Alam Nomor 2 Tahun 2012 tentang Pembangunan Sarana Pariwisata Alam di Taman Nasional, Taman Hutan Raya dan Taman Wisata Alam.

Peraturan Menteri Pariwisata Nomor 24 Tahun 2015 tentang Standar Usaha Bumi Perkemahan.

Pusat Standardisasi Lingkungan dan Kehutanan. 2015. Standar Pelayanan Masyarakat Pariwisata Alam. Jakarta: Kementerian Lingkungan Hidup dan Kehutanan.

Sekaran U. 2006. Metode Penelitian Bisnis. Jakarta: Salemba Empat.

Sugiyono. 2003. Metode Penelitian Administrasi. Bandung: Alfabeta.

.Wade DJ, Eagles PFJ. 2003. The use of importanceperformance analysis and market segmentation for tourism management in parks and protected areas: an application to Tanzanias National Parks. Journal of Ecotourism. 2 (3): 196-212.

Xue H, Fang C. 2018. How to optimize tourism destination supply: A Case in Shanghai from Perspective of Supplier and Demand Side Perception. Earth and Environmental Science. 113:012227. doi:10.1088/1755-1315/113/1/012227 